\title{
Correlation between echocardiographic and morphological investigations of lesions of the tricuspid valve diagnosed during fetal life
}

Sinderkardiologie

Universitaets-Kinder-

Klinik, Ulm, Germany R Oberhoffer

D Lang

Department of Pathology, Guy's

Hospital, London

A C Cook

N L K Fagg

Department of

Perinatal Cardiology,

Guy's Hospital,

London

G Sharland

L D Allan

National Heart and

Lung Institute,

London

R H Anderson

Correspondence to

Professor R H Anderson,

Department of Paediatrics,

National Heart and Lung

National Heart and Lung

London SW3 6LY.

Accepted for publication

27 April 1992

Renate Oberhoffer, Andrew C Cook, Dieter Lang, Gurleen Sharland, Lindsey D Allan, Nuala L K Fagg, Robert H Anderson

\begin{abstract}
Objective-To assess the degree of agreement between the fetal echocardiographic and postmortem examination of hearts from fetuses with severe malformations of the tricuspid valve.

Design-A retrospective study to analyse echocardiographic recordings and make comparisons with postmortem findings.
\end{abstract}

Setting-Tertiary referral centre for fetal echocardiography. Institute for cardiac morphology.

Patients-19 cases shown to have severe malformation of the tricuspid valve by fetal echocardiography that died in the prenatal or neonatal period.

Main outcome measures-Correlations between morphology and measurements made at echocardiography and necropsy.

Results-The echocardiographic diagnosis was Ebstein's malformation in seven and tricuspid valvar dysplasia in 12 fetuses. These findings were confirmed in six and eight cases at necropsy. In one false positive diagnosis of Ebstein's malformation, necropsy showed dysplasia of the leaflets of the tricuspid valve without displacement. In four cases with the echocardiographic diagnosis of valvar dysplasia, necropsy showed displacement, the hallmark of Ebstein's malformation. Associated malformations that are known to worsen prognosis were predicted correctly by echocardiography. Taking the mean duration of four weeks between echocardiographic and postmortem investigations, both methods showed cardiomegaly causing lung hypoplasia, right atrial dilatation, and relative hypoplasia of the pulmonary trunk, morphometric factors that may be responsible for the poor outcome. Mostly good agreement existed between the echocardiographic and postmortem measurements if cases with an interval of more than eight weeks between the measurements were excluded.

Conclusion Fetal echocardiography was proved to be a reliable technique in differentiating the variants of tricuspid valvar disease, in diagnosing associated cardiac lesions, and in predicting quantitative factors that can define the subsequent outcome.

(Br Heart J 1992;68:580-5)

It is now well recognised that echocardiography can diagnose structural heart disease with great reliability during fetal life. ${ }^{1}$ Thus rare congenital lesions, such as dysplasia and Ebstein's malformation of the tricuspid valve, lesions that may or may not overlap, can be differentiated. $^{2}$ The pathological spectrum of these two malformations in prenatal and neonatal life has also been described and discussed. ${ }^{3}$ In our study we have compared directly the findings of fetal echocardiography and morphology in defining the diagnoses in these previous investigations, ${ }^{23}$ and we have assessed those quantitative factors that may contribute to the outcome of these lesions.

\section{Patients and methods}

There are 19 examples of either Ebstein's malformation or dysplasia of the leaflets of the tricuspid valve in the cardiopathological museum of Guy's Hospital in which echocardiographic monitoring had been performed during fetal life and in which severe malformation of the tricuspid valve was detected. After the echocardiography, 10 mothers chose termination of the pregnancy, there were four spontaneous intrauterine, and five neonatal deaths. These 19 cases form the group that has now been studied morphologically. The collection at Guy's is not one that is representative of fetal disease, as a considerable bias is introduced by the concerted attempt to obtain all hearts diagnosed echocardiographically for study at necropsy. The hearts were taken for necropsy, therefore, ${ }^{3}$ because they had been studied echocardiographically. ${ }^{2}$

The age of the fetuses at the time of scanning ranged from 16 to 37 weeks, with a mean of 24.6 weeks. The age of the fetuses or neonates at death varied between 20 and 40 weeks of gestation, with a mean of 28.8 weeks. The interval between the echocardiographic examination and the death of the fetuses or neonates ranged from one to 12 weeks.

The echocardiographic studies had been conducted with an Advanced Technology Laboratory Mark III and Mark IV Scanner that had a $3 \mathrm{MHz}$ or a $5 \mathrm{MHz}$ transducer, or a Hewlett Packard 77020 A phased array scan- 
Figure 1 Differences between necropsy and echocardiographic measurements plotted against the mean for height of $R A$ in the same fetus. Only data from fetuses with less than eight weeks between the two measurements are included $(n=14$, mean $(S D)$ of the differences $=1.09 \mathrm{~mm}$ $(3 \cdot 70))$.

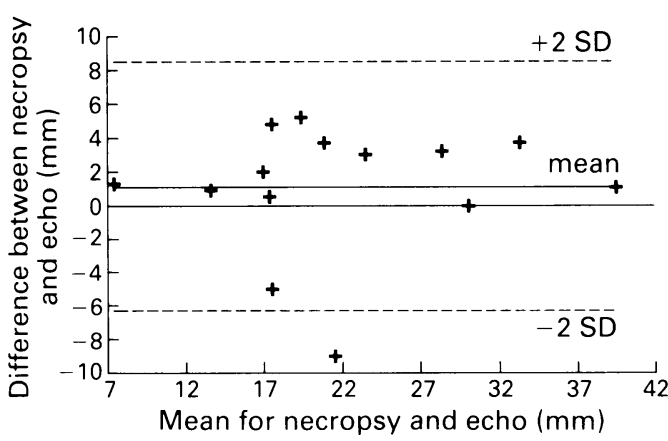

ner and a medium focus $5 \mathrm{MHz}$ transducer. For the purposes of this study, the videotapes of the echocardiograms were reviewed retrospectively and the findings were analysed with respect to displacement and dysplasia of the leaflets of the tricuspid valve, valvar stenosis or regurgitation as shown by Doppler studies, associated cardiac lesions, the cardiothoracic ratio, and the dimensions of the heart

Right and left atrial heights were estimated from a typical four chamber section as the maximal distance during ventricular systole from the atrioventricular groove to the posterosuperior wall of the atrium. Ventricular dimensions were measured in diastole as the distance from the atrioventricular junction to the apex of the ventricle. The diameters of the atrioventricular junctions were taken as the maximal diastolic dimensions. The postmortem measurements were made from the heart and lungs fixed in formalin after they had been separated and weighed. The thicknesses of the free walls of the right and left ventricles were measured in their inflow components. All hearts were then sectioned to simulate the echocardiographic four chamber planes and measurements were performed as already described.

The echocardiographic and pathological measurements were then compared with the normal values for similar duration of gestation..$^{4-6}$ As an anatomical correlation to the cardiothoracic ratio obtained echocardiographically, the ratio of the weight of the heart was taken against the combined weight of the heart and lung and related to normal values.

To assess the agreement between echocardiographic and postmortem measurements, we plotted the difference between the methods against their mean as described by Bland and Altman. ${ }^{8}$ For the right atrium this is shown in a graph (fig 1), but for all the other measurements the mean difference was listed in the table.

\section{Results}

CORRELATIONS BETWEEN ECHOCARDIOGRAPHY AND MORPHOLOGY

During fetal life, Ebstein's malformation had been diagnosed in seven fetuses (fig 2A) and tricuspid dysplasia in 12 cases (fig 3A). At postmortem examination, these results were confirmed in six (fig 2B) and eight (fig 3B) cases respectively. One single false positive diagnosis of Ebstein's malformation was made in a fetus at 19 weeks gestation, in which necropsy showed gross dysplasia of the leaflets of the tricuspid valve without displacement. Isolated tricuspid valvar dysplasia was predicted in three fetuses, in which the leaflets of the tricuspid valve were, indeed, severely malformed and would have been the major cause of tricuspid incompetence. There was, however, a minimal displacement of about $5 \mathrm{~mm}$ of the mural and the septal leaflets in two, and major displacement of the mural leaflet with linear distal attachment of the anterosuperior leaflet in the other (fig 4A). The pathological diagnosis of each case, therefore, was Ebstein's malformation together with valvar dysplasia. The fourth
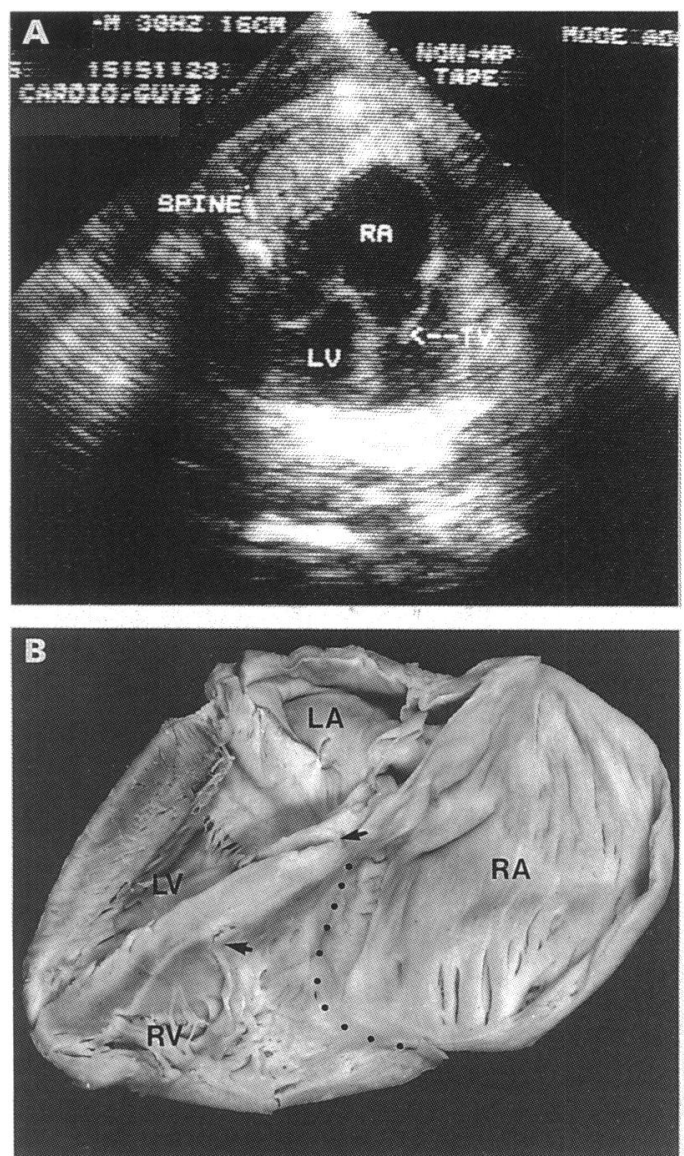

Figure 2 (A) Echocardiographic view in four chamber plane shows Ebstein's malformation in a 37 week old fetus. $R A$ is grossly dilated and the hinge point of septal leaflet of the TV arises well down (arrow) the ventricular septum. (B) Pathological specimen of the same fetus has been photographed and printed in reverse so as to replicate the echocardiographic orientation. It confirms the noticeable displacement of the septal leaflet of the TV (arrows), which arises some distance from the

atrioventricular junction (dotted line). LA, left atrium; $L V$, left ventricle; $M V$, mitral valve; $R A$, right atrium, $R V$, right ventricle; $T V$, tricuspid valve.
Eight week difference is the mean difference in which only fetuses with an interval of less than eight weeks are included. $n$, number of cases; RA, right atrium; LA, left atrium; RV, right ventricle; $\mathrm{LV}$, left ventricle; $\mathrm{TV}$, tricuspid valve; $\mathrm{MV}$, mitral valve; $\mathrm{PA}$, pulmonary artery; $\mathrm{AO}$, aorta; CTR, cardiothoracic ratio.

Mean ( $S D$ / measurements made echocardiographically and at necropsy and their mean difference

\begin{tabular}{|c|c|c|c|c|c|c|c|c|}
\hline & $n$ & Echo & $n$ & Specimen & $n$ & Difference & $n$ & Eight week difference \\
\hline $\mathrm{RA}(\mathrm{mm})$ & 18 & $21 \cdot 6(8.9)$ & 18 & $23 \cdot 7(11 \cdot 6)$ & 18 & $2.97(8.0)$ & 14 & $1.09(3 \cdot 7)$ \\
\hline $\mathrm{LA}(\mathrm{mm})$ & 17 & $12 \cdot 5(4 \cdot 2)$ & 19 & $14.8(4.9)$ & 17 & $2 \cdot 66(4 \cdot 4)$ & 13 & $1.51(3.7)$ \\
\hline $\mathrm{RV}(\mathrm{mm})$ & 18 & $17 \cdot 3(6 \cdot 4)$ & 18 & $21 \cdot 1(7 \cdot 3)$ & 18 & $4 \cdot 28(4 \cdot 4)$ & 14 & $3.95(4.5)$ \\
\hline $\mathrm{LV}(\mathrm{mm})$ & 18 & $17 \cdot 4(6 \cdot 6)$ & 19 & $21.7(7 \cdot 6)$ & 18 & $4 \cdot 74(4.9)$ & 14 & $2.90(3.7)$ \\
\hline $\mathrm{TV}(\mathrm{mm})$ & 18 & $12 \cdot 1(5 \cdot 2)$ & 18 & $13.0(5.9)$ & 17 & $0.95(4.8)$ & 13 & $0 \cdot 17(4 \cdot 2)$ \\
\hline $\mathrm{MV}(\mathrm{mm})$ & 18 & $9 \cdot 4(4 \cdot 7)$ & 18 & $8 \cdot 3(3 \cdot 2)$ & 17 & $-1.13(3.3)$ & 13 & $-1 \cdot 19(3 \cdot 1)$ \\
\hline $\mathrm{PA}(\mathrm{mm})$ & 18 & $3.87(2.0)$ & 19 & $5 \cdot 26(3 \cdot 0)$ & 18 & $1.6(2 \cdot 1)$ & 14 & $0.7(2 \cdot 3)$ \\
\hline $\mathrm{AO}(\mathrm{mm})$ & 18 & $5.72(1.9)$ & 19 & $6 \cdot 23(2 \cdot 8)$ & 18 & $0.63(2 \cdot 5)$ & 14 & $0.02(1 \cdot 1)$ \\
\hline PA/AO & 18 & $0.68(0.19)$ & 19 & $0.84(0.33)$ & 18 & $0.22(0 \cdot 19)$ & 14 & $0 \cdot 19(0 \cdot 18)$ \\
\hline CTR & 19 & $0.68(0.11)$ & 19 & $0.44(0.11)$ & & & & \\
\hline
\end{tabular}


Figure 3 ( $A$ )

Echocardiographic view in four chamber plane shows a dysplastic TV but with normal junctional attachments of the leaflets. (B) The four chamber view of the heart of the same fetus confirms the gross dilatation of the $R A$ and shows the normal junctional attachments of the TV and mitral valves with offsetting at the septum: there is gross nodular dysplasia of the mural and septal leaflets (arrows).
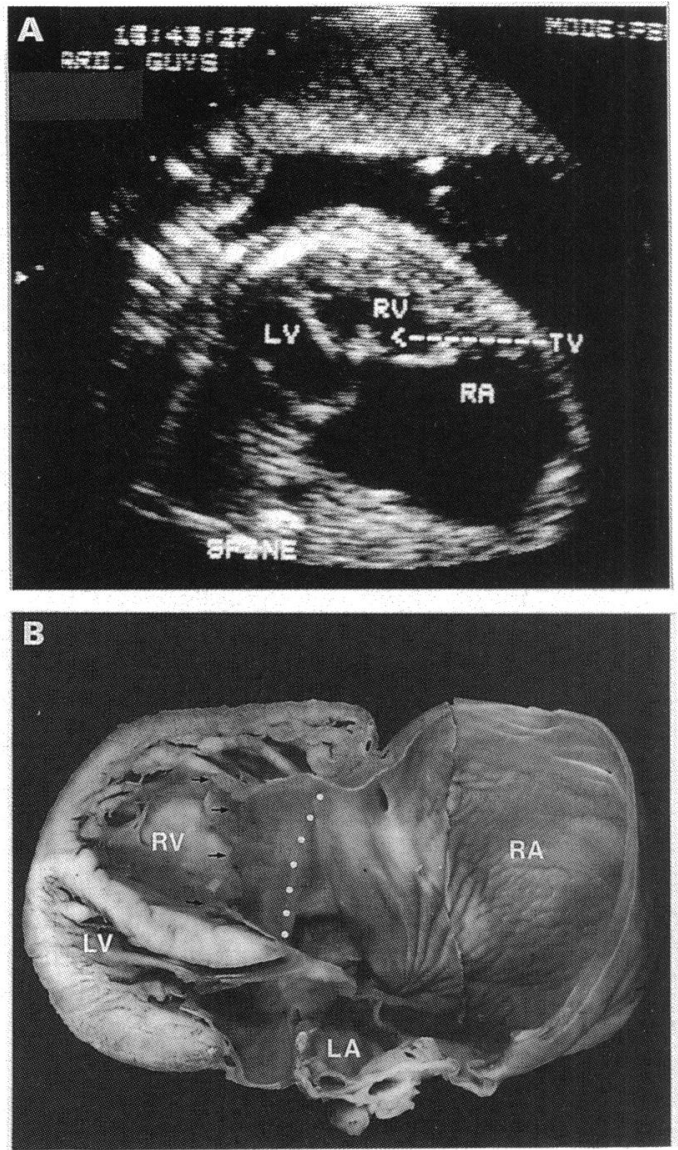

case, in which Ebstein's malformation had not been found echocardiographically, showed displacement of the septal and mural leaflets, but with a most unusual dual formation of both leaflets (fig 4B). Some degree of tricuspid valvar dysplasia was appreciable echocardiographically in most cases irrespective of the diagnosis, and corresponded well with the extent of dysplasia estimated by gross examination of the necropsied specimens. ${ }^{3}$ Among the cases with Ebstein's malformation in which downward displacement of the leaflets had been documented, it was not possible, in three cases, to diagnose echocardiographically the absence of the septal or the mural leaflet. Furthermore, the nature of the distal attachments of the tension apparatus (linear, (fig 4A), hyphenated, or focal) was not reliably classified by fetal echocardiography. Doppler echocardiography during fetal life showed signs of tricuspid regurgitation in all but one fetus, and no case showed evidence of stenosis.

In terms of associated malformations; the presence of one ventricular septal defect had been correctly predicted by fetal echocardiography; one additional small ventricular septal defect had been seen in one fetus when studied at the age of 20 weeks, but could not be located when the specimen was obtained at 24 weeks.

Prediction of atrial septal defects during fetal life is complicated by the patency of the oval foramen and such lesions were not recorded echocardiographically in this study. On postmortem examination, however, six atrial septal defects were found in each group. The atrioventricular and ventriculoarterial connections were discordant in two hearts with Ebstein's malformation (congenitally corrected transposition (fig 5)). These diagnoses had been made correctly during fetal life.

Eight cases of pulmonary atresia, and one case of pulmonary stenosis, were correctly predicted echocardiographically. No obstruction within the right ventricular outflow tract was found on postmortem examination in another two cases, one in which pulmonary atresia and the other in which pulmonary stenosis had been diagnosed prenatally. Two additional instances of pulmonary stenosis were found on postmortem examination. Some degree of mitral valvar dysplasia was encountered at necropsy in four hearts, three of which also had tricuspid dysplasia, which was not seen at echocardiographic examination in two fetuses. An example of divided right atrium (cor triatriatum dexter) was found in one case at necropsy. ${ }^{3}$

CORRELATIONS OF ECHOCARDIOGRAPHIC AND NECROPSY MEASUREMENTS

The results of the echocardiographic and necropsy measurements are expressed as the mean (SD) and the comparison between the two measurements is given by the mean difference according to Bland and Altman (table). ${ }^{8}$

Compared with the left atrium, the right was dilated in all hearts (except the two hearts with discordant atrioventricular connections, in

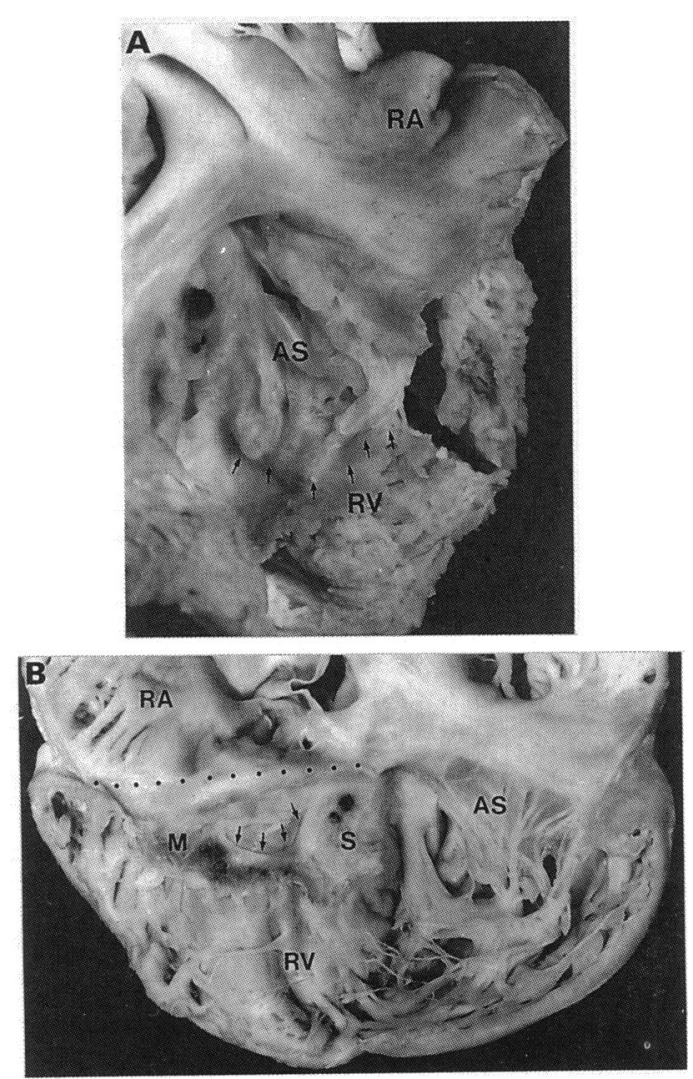

Figure 4 (A) Towards the right ventricular outflow tract in the heart from a 27 week old fetus there is linear attachment of the AS leaflet of the TV (arrows).

(B) The right atrium and ventricle of another heart are opened to show downward displacement and dual opened to show downward displacement and dual anterosuperior leaflet; $M$, mural; $S$, septal. 
Figure 5 (A) These corresponding four chamber views of the heart with congenitally corrected transposition seen during fetal life and $(B)$ on postmortem examination show gross downward displacement of the hinge points of the $S$ and $M$ leaflets of the TV away from the atrioventricular junction (arrows). Note the dilatation of the left atrium.
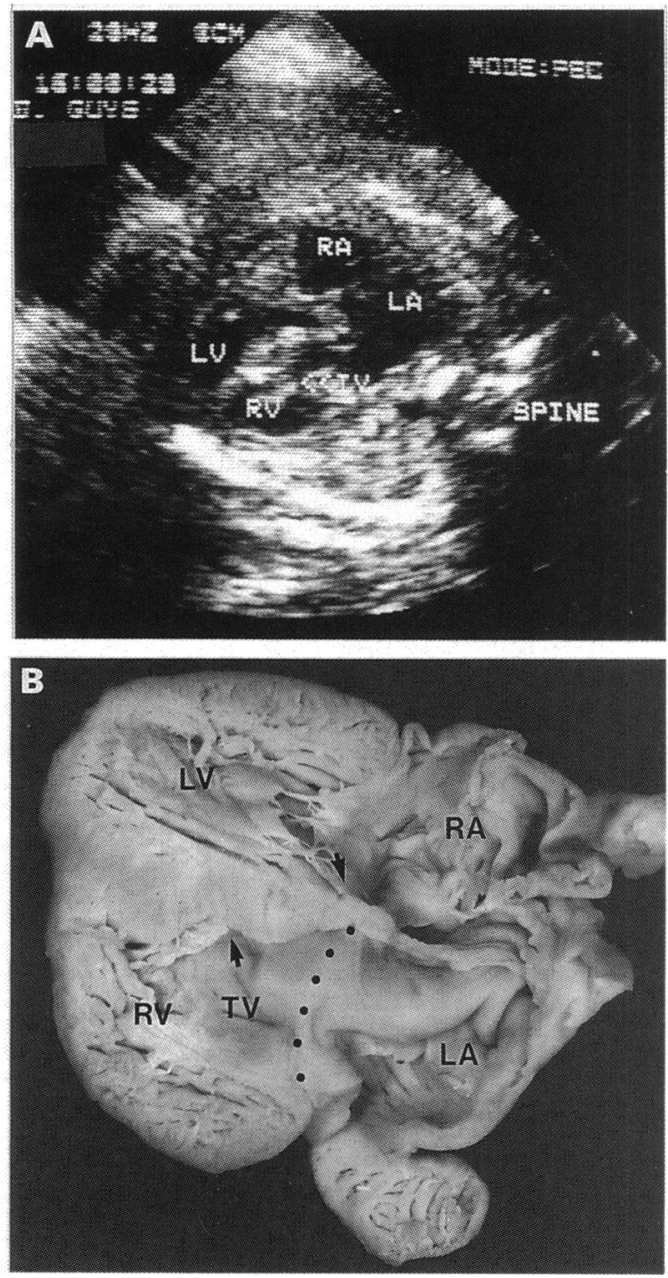

which the left atrium was larger). Echocardiographically, the mean height of the right atrium (or left atrium with discordant connections) was $21.6 \mathrm{~mm}$ whereas that of the left (or right atrium with discordant connections) was $12 \cdot 5$ $\mathrm{mm}$. The corresponding values measured in the necropsied specimens were 23.7 and 14.8 $\mathrm{mm}$. The mean (SD) difference of the two measurements for the height of the right atrium was $2.97(0.8) \mathrm{mm}$. If the fetuses with an interval between the two measurements $>$ eight weeks were not included in the calculation, however, there was a good agreement between the two methods (values marked with an asterisk in the table and the text) for the right atrium (fig 1) as well as for most of the other dimensions.

There was a non-significant difference between the echocardiographic and necropsied length of the right and the left ventricles, shown by a mean difference of $4 \cdot 28\left(3 \cdot 95^{\star}\right) \mathrm{mm}$ for the right and $4 \cdot 74\left(2 \cdot 90^{\star}\right) \mathrm{mm}$ for the left ventricle.

The tricuspid valve was larger in diameter than the mitral valve (mean $12 \cdot 1 v 9.4 \mathrm{~mm}$ ) as determined by echocardiographic measurement as well as in the anatomical measurement (mean 13.0 $8.3 \mathrm{~mm}$ ). Good agreement was found between the two methods of measurement for the tricuspid as well as for the mitral valve (table). When compared with mean values of the normal fetus, ${ }^{4}$ the echocardiographic measurement showed enlargement of both atrioventricular valves in all but two hearts. Good agreement between the two methods was also shown for the diameter of both great arteries with a mean difference of 1.6 $\left(0.7^{\star}\right)$ for the pulmonary trunk and $0.63\left(0.02^{\star}\right)$ for the aorta. The ratio of the diameter of the pulmonary and aortic roots was reduced in all fetal scans as it was at necropsy, but at a lower degree leading to a mean difference of 0.22 $\left(0 \cdot 19^{\star}\right)$. The values were below expected normal measurements in 15 of 19 fetuses.

The cardiothoracic ratio as determined echocardiographically was increased in all but one fetus (mean: 0.68 ) when compared with values for the normal fetus. ${ }^{6}$ The postmortem equivalent of the cardiothoracic ratio, obtained by calculating the ratio of the weight of the heart to the combined weight of heart and lungs, was also greatly increased, with a mean of 0.44 compared with a normal range of 0.25 to $0 \cdot 30 .{ }^{7}$ Noticeable reduction in the thickness of the wall of the inlet component of the right ventricle was found at necropsy in six hearts with Ebstein's malformation and in three with tricuspid dysplasia. None of the previous measurements showed any correlation with this mural thinning.

Apart from the diameter of the mitral valve, the measurements taken from the specimens exceeded the values obtained by echocardiography.

\section{Discussion}

Congenital malformations of the tricuspid valve are known to show a gradation of changes, ranging from Ebstein's malformation with downward displacement of the valvar leaflets in isolation, through combinations of displacement and dysplasia, to exclusive dysplasia of normally attached leaflets. ${ }^{6}$ Irrespective of the combinations, our previous studies have shown that differentiation of dysplasia and displacement is possible in most cases, even in prenatal life. ${ }^{23}$ Our present study, combined with our previous investigations, ${ }^{23}$ shows that prenatal ultrasound in our hands is a reliable method of diagnosing the malformation of the tricuspid valve in their different variations and in assessing the sizes of chambers and vessels. Thus different combinations of malformations afflicting the tricuspid valve may be readily defined by means of fetal echocardiography even before the midpoint of gestation. Failure to differentiate the two lesions was, apart from one case, related to lack of recognition of minor degrees of valvar displacement in Ebstein's malformation, or to the presence of extremely rare malformations of the valve, such as dual formation of the leaflets. This is difficult to assess echocardiographically even in postnatal life. The most common haemodynamic abnormality in either Ebstein's malformation or tricuspid dysplasia is valvar regurgitation as caused by dysplasia or even absence of the leaflets. ${ }^{10}$ Echocardiographic determination of the degree of dysplasia was usually correct, whereas detection of lack of the leaflets was not. This is not unexpected, as recognition of absence of leaflets is rare at present during 
postnatal life. ${ }^{11}$ The haemodynamic consequence of these anomalies, none the less, can be shown with precision by Doppler echocardiography, which showed tricuspid regurgitation in all fetuses. The combination of atrioventricular valvar insufficiency and structural heart disease is important to recognise, as it is known to indicate a poor prognosis in fetal life, especially when this results in cardiac failure prenatally. ${ }^{12}$

Even in prenatal and neonatal hearts, the cardinal feature of displacement in Ebstein's malformation is always confined to the septal and mural leaflets. ${ }^{3}$ The anterosuperior leaflet of the valve, attached normally at the atrioventricular junction, was noted to have linear attachments of the distal tension apparatus in three fetuses of each group. ${ }^{3}$ Recognition of this feature is particularly important in postnatal life, as, when present, it may cause a degree of obstruction between the inlet and outlet portions of the right ventricle. ${ }^{13}$ Such stenosis has been correlated with early death (by three months) in infants with Ebstein's malformation. ${ }^{14}$ It is the subcostal coronal view that in postnatal life is the most reliable to show the anterosuperior leaflet. Similar views will be needed during fetal life if in future there is need to distinguish between focal and linear attachment of the anterosuperior leaflet. With respect to flow across the valve, Doppler techniques showed only regurgitation in most fetuses. Even recognising the known caveats of underestimation of the degree of obstruction, stenosis due to distal tethering was most unlikely in our cases as all leaflets were seen to be in motion and the atrioventricular junction was dilated. ${ }^{13}$

The association with other cardiac lesions is known to make the prognosis in Ebstein's malformation worse. ${ }^{13}$ Because of the comparable haemodynamic consequences, this seems likely also to be the case with tricuspid dysplasia. When there was an associated malformation there was no discrepancy between prenatal and postmortem diagnoses of deficiencies of the ventricular septal structures or in the recognition of discordant atrioventricular and ventriculoarterial connections. A small ventricular septal defect was not found on the postmortem examination of one case in which it had been diagnosed echocardiographically. We presume that it had closed spontaneously during the subsequent intrauterine life. ${ }^{1}$ Atrial septal defects are difficult to predict during fetal life because of the patency of the foramen ovale. Correlation of that feature with the postmortem specimens, therefore, was not attempted. Minor degrees of dysplasia of the leaflets of the mitral valve were noted in some hearts at necropsy, a feature known to accompany Ebstein's malformation when seen in postnatal life. ${ }^{915}$ To our knowledge, these lesions have not previously been described in tricuspid valvar dysplasia. Perhaps not surprisingly, these minor abnormalities were not recognised during fetal echocardiography. As the degree of dysplasia was mild, we do not anticipate it to have had any haemodynamic implications. This fact also held true in one case with division of the right atrium due to persistence of the valves of the embryonic venous sinus. This feature had not been noted on cross sectional echocardiography. In haemodynamic terms, this lesion is simply an exaggeration of the anatomical arrangement usually found during fetal life and augments the right to left atrial shunt already present.

Severe obstruction at the level of the pulmonary valve was seen in two fifths of the hearts with Ebstein's malformation and in two thirds of those with valvar dysplasia. The higher incidence of obstructive lesions of the right ventricular outflow tracts has already been described in pure tricuspid dysplasia, ${ }^{29}$ and may contribute to the poor overall outcome in this group. ${ }^{9}$ Although it is extremely difficult to distinguish organic atresia from the situation where the leaflets of the pulmonary valve are held closed by the high pressure in the pulmonary arteries, ${ }^{13}$ pulmonary atresia was correctly predicted by means of fetal echocardiography in nearly all cases. Even beyond functional atresia, recognition of pulmonary stenosis in itself may easily be a source of error at fetal scans. This is because sequential studies have shown that Doppler gradients across the pulmonary valve may increase during fetal life, ${ }^{2}$ and that stenosis can progress to atresia. ${ }^{16} \mathrm{It}$ is important, therefore, to note that the severity of cardiac lesions can progress during fetal life, and that the anatomical and the haemodynamic situation can change between the time of fetal scanning and when specimens are studied postnatally. ${ }^{1}$ Taking this into consideration, the fetal echocardiographic diagnosis of malformations of the tricuspid valve and of associated cardiac anomalies shows good agreement with the findings at necropsy. Some minor disagreements are probably unavoidable but are mainly of academic interest or have minimal effects on prognosis. ${ }^{1}$

In this series, we have also analysed cardiac dimensions as determined by ultrasound and compared them with the known normal values. We have further related them to predictors of outcome well established in children and adults with Ebstein's malformation, comparing them then with the measurements obtained at postmortem. The most important predictive feature is the size of the heart. The cardiothoracic ratio was increased above the normal range ${ }^{14}$ in all fetuses in our series, irrespective of whether they showed Ebstein's malformation or tricuspid valvar dysplasia, and was caused predominantly by enlargement of the right atrium. It has been assumed that cardiomegaly causes secondary hypoplasia of the lungs in the fetus, ${ }^{217}$ thus increasing the risk of death due to hypoxia. Postmortem analysis of the weights of the lungs and heart in this series has already shown that the weight of the hearts was unequivocally increased, ${ }^{3}$ whereas the weights of the lungs were within the lower range of normal. Echocardiographic measurements reflected areas, whereas the postmortem values represented weights, so the two cannot be compared. Nevertheless, the ratio based upon weight, with a mean of 0.44 , is greatly 
increased compared with the normal ratio of $0 \cdot 25$ to $0 \cdot 30$ for the appropriate fetal age. ${ }^{7}$ Thus, both sets of measurements reflect the cardiomegaly and the relatively small size of the lungs, which are almost certainly responsible for their inadequate functional capacity after birth. ${ }^{18}$

Prenatal and postmortem investigations of dimensions of chambers and vessels showed good agreement if the time between the measurements was small. It is hardly surprising that echocardiographic measurements were smaller than those from necropsy, as there was a mean period of four weeks between the two sets of investigations.

Keeping this restriction in mind, gross right atrial dilatation, claimed to be an important risk factor for early death in fetuses and newborns with Ebstein's malformation, ${ }^{12}$ was correctly predicted by fetal echocardiography. Left ventricular compression as a consequence of dilatation of the right ventricle, also defined as a morphological risk factor, ${ }^{12}$ was not found in our series. This may be caused partly by the different sites at which measurements were made.

In most specimens, irrespective of the diagnosis, considerable reduction was noted at necropsy in the thickness of the right ventricular wall, a feature not measured during the prenatal studies. As this finding is also recognised as a sign of poor clinical outcome in Ebstein's malformation, ${ }^{12}$ it may be worth including in future fetal echocardiographic examinations.

Comparing fetal echocardiography with the postmortem morphological evaluation, therefore showed good agreement in differentiating Ebstein's malformation from dysplasia of the leaflets of the tricuspid valve and in defining associated cardiac lesions. Future examinations might include measurements of the thicknesses of the ventricular walls and estimations by Doppler echocardiography of mitral valvar flow. These could also serve as prognostic determinants of abnormalities of the tricuspid valve. During the course of this investigation, RO and DL were
visiting colleagues at the National Heart and Lung Institute. RO is supported by the Deutsche Forschungsgemeinschaft, Bonn.
ACC, NLKF, LDA, CS and RHA are all supported by the British Heart Foundation, together with the Joseph Levy Foundation in the case of RHA.

1 Allan LD, Chita SK, Sharland GK, Fagg NLK, Anderson RH, Crawford DC. The accuracy of fetal echocardio$\mathrm{RH}$, Crawford DC. The accuracy of fetal echocardio-
graphy in the diagnosis of congenital heart disease. Int $J$ Cardiol 1989;25:279-88.

2 Sharland GK, Chita SK, Allan LD. Tricuspid valve dysplasia or displacement in intrauterine life. J Am Coll Cardiol 1991;17:944-9.

3 Lang D, Oberhoffer R, Cook A, Sharland GK, Allan LD, Fagg NLK, Anderson RH. The pathological spectrum of malformations of the tricuspid valve in pre- and neonatal life. J Am Coll Cardiol 1991;17:1161-7.

4 Allan LD, Chita SK, Al-Ghazali W, Crawford DC, Tynan MJ. Doppler echocardiographic evaluation of the norma human fetal heart. Br Heart $J$ 1987;57:528-33.

5 Allan LD, Crawford DC, Tynan MJ. Pulmonary atresia in prenatal life. J Am Coll Cardiol 1986;8:1131-6.

6 Palladini D, Chita SK, Allan LD. Prenatal measurement of the cardiothoracic ratio in the evaluation of heart disease. Arch Dis Child 1990;65:20-3.

7 Potter EL, Craig J. Pathology of the fetus and infant. 3rd ed. Chicago: Year Book Medical, 1972:18-20.

8 Bland JM, Altman DG. Statistical method for assessing agreement between two methods of clinical measurement.

9 Becker AE, Becker MJ, Edwards JE. Pathologic spectrum of dysplasia of the tricuspid valve, features in common with Ebstein's malformation. Archives of Pathology 1971;91: 167-78.

10 Zuberbuhler JR, Anderson RH. Ebstein's malformation of the tricuspid valve: morphology and natural history. In Anderson RH, Neches WH, Park SC, Zuberbuhler JR eds. Perspectives in pediatric cardiology. Vol I. Mount Kisco, New York: Futura 1988:99-112.

11 Anderson RH, Silverman NH, Zuberbuhler JR. Congenitally unguarded tricuspid orifice-its differentiation from Ebstein's malformation in association with pulmonary atresia and an intact ventricular septum. Pediatr ary atresia and an intact
Cardiol 1990;11:86-90.

12 Silverman NH, Kleinmann CS, Rudolph AM, Copel JA Weinstein EM, Enderlein MA, Golbus M. Fetal atrioventricular valve insufficiency associated with nonimmune hydrops. Circulation 1985;72:825-32.

13 Silverman NH, Birk E. Ebstein's malformation of the tricuspid valve: cross sectional echocardiography and Doppler. In: Anderson RH, Neches WH, Park SC, Zuberbuhler JR eds. Perspectives in pediatric cardiology Vol I. Mount Kisco, New York: Futura 1988:113-25.

14 Roberson DA, Silverman NH. Ebstein's anomaly: echocardiographic and clinical features in the fetus and neonate. J Am Coll Cardiol 1989;14:1300-7.

15 Shiina A, Seward JB, Edwards WD, Hagler DJ, Tajik AJ Two dimensional echocardiographic spectrum of Ebstein's anomaly: detailed anatomic assessment. $J \mathrm{Am}$ Coll Cardiol 1984;3:356-70.

16 Todros T, Presbitero P, Gaglioro P, Demarie D. Pulmonary stenosis with intact ventricular septum: documentation of development of the lesion echocardiographically during fetal life. Int J Cardiol 1988;19:355-60.

17 Allan LD, Tynan M, Campbell S, Anderson RH. Norma fetal cardiac anatomy - a basis for the echocardiographic fetal cardiac anatomy - a basis for the echocardiograph

18 Sahn DJ, Heldt GP, Reed KL, Kleinmann CS, Meijbomm EJ. Fetal heart disease with cardiomegaly may be associated with lung hypoplasia as a determinant of poor prognosis. J Am Coll Cardiol 1988;11:9. 